\title{
Breve caracterización del sistema financiero canadiense
}

\author{
DOI: $10.32870 /$ mycp.v3i10.653
}

$\mathrm{E}$ 1 sistema financiero canadiense ha sido, y sigue siendo, desarrollado y eficiente. Está libre de los controles, regulaciones y distorsiones que han caracterizado a los mercados financieros de muchas otras economías avanzadas. En un estudio del sistema financiero canadiense, la Organización para la Cooperación y Desarrollo Económico expresó que: "Los mercados financieros canadienses han mostrado flexibilidad y capacidad para adaptarse a las necesidades cambiantes de los proveedores y los usuarios de fondos prestables, así como cierta disposición para la innovación. Todos los aspectos de la intermediación han estado presentes y activos, y no se ha restringido el acceso directo a los mercados de capital por parte de empresas e individuos. Tradicionalmente, las autoridades se han abstenido de interferir en la determinación de la cantidad o el precio del crédito, y sólo se han impuesto restricciones mínimas a la inversión en valores extranjeros."1

Sin embargo, Canadá se ha visto también afectado por la tendencia mundial a la reforma del mercado financiero. La reforma ha sido impuesta en Canadá por los mismos factores que han operado en otros países: la adaptación del marco regulador a los cambios estructurales y funcionales dados en los mercados financieros, la respuesta a la creciente globalización e integración de los servicios financieros, y el aseguramiento de la solidez de las instituciones financieras en épocas de creciente tensión y presión. La última meta tiene una importancia especial en vista de los crecientes problemas que afligen a los bancos canadienses desde el principio de los ochenta.

* Directora de Investigación Interdisciplinaria y Posgrado en la Universidad Autónoma de Baja California Sur.

** Investigador de la Universidad Autónoma de Baja California Sur.
Antonina Ivanova* y Osvaldo Ramírez**

El sector financiero de Canadá es relativamente grande y típico de un sistema financiero avanzado. El total de los activos financieros respecto al PIB guarda aproximadamente una razón de 4.4 a 1 , cifra similar a la de Estados Unidos, pero considerablemente mayor que la de Alemania o Italia (3.6 y 3.9, respectivamente). Los activos intermedios constituyen 41 por ciento del total de los activos financieros, una cifra ligeramente mayor que la de Estados Unidos (38 por ciento), pero mucho menor que la de Alemania (47 por ciento), donde el papel desempeñado por la banca universal alemana ha subido esta razón. Los mercados de capital directo han estado bien desarrollados desde hace largo tiempo, de modo que la participación de los valores en el total de los flujos de crédito (49.4 por ciento en 19841985) no es sólo mayor que en Alemania o en Francia (35.4 y 42.5 por ciento, respectivamente) sino también mayor que en Estados Unidos (46.7 por ciento).

La razón del ahorro familiar declinó en Canadá durante los años ochenta, llegando a cerca de 11 por ciento en 1989; mientras que el sector corporativo, tradicionalmente un prestatario neto, ha venido disminuyendo su déficit. El sector público incrementó también su endeudamiento neto durante los ochenta. Como resultado de estos desarrollos, Canadá, que había sido un exportador neto de capital a principios de los ochenta, vio revertirse esta tendencia a fines de esa década.

Resulta interesante observar que la conversión del sector público en un gran prestatario estructural, y el incremento consiguiente de las obligaciones directas emitidas por el gobierno, no provocaron ninguna reducción de la intermediación. Por el contrario, se demostró la madurez del sistema canadiense cuando las obligaciones gubernamentales sustituyeron a otras directas en las carteras privadas, mientras que el público había ajustado 
desde largo tiempo atrás su cartera a la combinación deseada de créditos directos e indirectos. Si acaso, parece haber aumentado ligeramente el peso de créditos intermedios, al acentuarse la preferencia del público por los activos financieros a corto plazo (debido a la rápida inflación y a las bajas tasas de interés reales) y los fondos de pensión y de jubilación (debido al tratamiento fiscal preferente).

La estructura tradicional del sistema financiero canadiense se conoce ampliamente como el Marco de los Cuatro Pilares: bancos certificados, semibancos (otras instituciones receptoras de depósitos), compañías de inversiones y compañías de seguros. Es claro que esto constituye un sistema de separación estructural de la intermediación financiera por función y por producto, similar al del Reino Unido, y al de los Estados Unidos, y diferente del modelo europeo del banco universal. Aunque la separación funcional es clara, no hay ningún elemento de restricción geográfica como en los Estados Unidos; en efecto, la mayoría de los intermediarios financieros opera en Canadá a nivel nacional.

Los bancos certificados comparables a los bancos comerciales eran 66 en julio de 1989, y su número, debido a las fusiones que se han dado en los últimos años, disminuye a 49 en julio de 2000. Éstos poseen cerca de 72 por ciento de los activos del sector bancario. De acuerdo con la Ley Bancaria de 1980 los bancos se clasificaron en la Cédula A (siete bancos nacionales de propiedad generalizada) o en la Cédula B (59 bancos nacionales y extranjeros de propiedad restringida). En 1988 estas categorías se cambian a Cédula I y Cédula II, respectivamente. ${ }^{2}$ Los bancos de la segundas categoría tienen las mismas facultades que las de la primera, excepto por algunas restricciones en cuanto al tamaño y el número de sucursales.

Los más importantes bancos de la Cédula I son los seis mayores bancos nacionales, los que dominan el sector bancario con cerca de 6700 sucursales y 90 por ciento de los activos de los bancos certificados. Los seis bancos mayores se encuentran entre los 100 más grandes del mundo. Los demás de la Cédula I son dos bancos regionales. Tal como ha evolucionado en Canadá, el sistema bancario incluye grandes redes de sucursales que llevan el capital de las instituciones citadinas a remotos pueblos y aldeas.

Las 36 subsidiarias de bancos extranjeros (sólo hay un banco nacional de propiedad restringida), que están constituidas como bancos certificados de la Cédula II, operan en los términos de la Ley Bancaria de 1980. Además hay reglas y regulaciones especiales que se aplican específicamente a los bancos extranjeros.

El segundo pilar de la estructura financiera, el de las compañías fiduciarias y las de préstamos hipotecarios, puede llamarse el $d$. los semibancos. Aunque los dos grupos tien€n un origen distinto, a través del tiempo se han convertido en instituciones muy similares. En gran medida han llegado a asemejarse a los bancos comerciales. Las funciones bancarias de las compañías fiduciarias incluyen el financiamiento a través de los ahorros y los depósitos a plazo la emisión de certificados de inversión garantizados y las inversiones de hipotecas, valores de alto grado y préstamos avalados. Por oposición a los bancos certificados, las compañías fiduciarias no están obligadas a mantener reservas sin intereses en el banco central. Sin embargo, sus préstamos comerciales se limitan a 7 por ciento de sus activos totales. Las compañías fiduciarias son peculiares por cuanto pueden realizar actividades fiduciarias. Esto les permite, por ejemplo, administrar inmuebles y fideicomisos y proveer servicios de administración de carteras e inmuebles.

Las compañías de préstamos hipotecarios se financian primordialmente mediante la aceptación de depósitos a plazo y la emisión de 
pagarés. En su mayor parte son subsidiarias de compañías fiduciarias o de bancos certificados. En virtud de que las compañías de préstamos no están sujetas al encaje legal del Banco de Canadá, se utilizan para canalizar préstamos hipotecarios con mayor rentabilidad.

Varias instituciones más pequeñas tienen papeles especializados, tales como las uniones de crédito propiedad de cooperativas (llamadas Caisses Populaires en Quebec), instituciones de ahorro y préstamo, compañías financiadoras de ventas y compañías de préstamos a consumidores.

Los pilares no bancarios incluyen tradicionalmente a las compañías de inversiones y las compañías de seguros. Las compañías de inversiones, similares a los bancos de inversión de Estados Unidos y los bancos mercantiles del Reino Unido asisten a sus clientes corporativos en lo referente a sus necesidades de financiamiento y de capital. Esto se hace casi exclusivamente mediante de transacciones con valores tales como los avales, la distribución y el mercadeo. Parece probable que se incremente en el futuro el papel de las compañías de inversiones en la estructura financiera, en vista de la creciente valorización de los mercados financieros. En cambio, declina claramente el papel de las compañías de seguros; su participación en el total de los activos intermedios disminuyó de 18 por ciento en 1965 a 14 por ciento en 1998. Los programas de anualidades y ahorros ofrecidos por las compañías de segu-ros no han resultado atractivos frente a la competencia creciente de otras fuentes y la preferencia generalizada por los activos líquidos a corto plazo.

Fuera de la estructura tradicional de los cuatro pilares, varias instituciones financieras especializadas, relativamente nuevas, han empezado a desempeñar un papel importante como intermediarios financieros. Se incluyen aquí los fondos de pensión, los fondos mutualistas, las compañías arrendadoras y las firmas de capital de riesgo. Los fondos de pensiones, en particular, han atraído una porción creciente de los activos familiares, desempeñando un papel muy importante en el financiamiento corporativo.

A pesar del alto grado de concentración en la industria bancaria de Canadá, la competencia no se ha reducido mucho. Esto se debe ante todo a la capacidad de diversos tipos de instituciones para competir por negocios bancarios que son muy semejantes. Por ejemplo, los servicios bancarios personales se ofrecen por los bancos certificados, las compañías fiduciarias y las compañías de préstamos hipotecarios.

Es probable que las numerosas reformas y los cambios de la regulación que se han implantado o propuesto en los últimos años, aunados a los desarrollos del mercado, anuncien un cambio continuo en la estructura institucional de los mercados financieros canadienses.

\section{Notas}

1. OECD Economic Surveys, Canadá, 1986/1987, 15-59.

2. La principal diferencia entre los dos tipos de bancos es su propiedad. Las acciones de los bancos de la Cédula I están ampliamente repartidas, de modo que nadie posee más de 10 por ciento. Las acciones están en manos del público y se inscriben en todas las bolsas de valores canadienses.

\section{Fuentes}

Banco de Canadá, Review, varios números; Guttman, Robert (Ed.) Reforming Money and Finance, M.E. Sharpe, USA, 1997; OECD, Economic Surveys, Canadá, 1997/98. 1998/1999; Statistics Canada, Cansim, Matriz 4285 y Catálogo 72-00-XPB; Supplement to Canada Gazette, OSF, 1999; Swary Itzhak y Barry Topf. La desregulación financiera global. La banca comercial en la encrucijada; Fondo de Cultura Económica, México, 1993; www. Interac.org; www.cba.ca 